ASTHMA

\title{
Double blind randomised controlled trial of two different breathing techniques in the management of asthma
}

\author{
C A Slader, H K Reddel, L M Spencer, E G Belousova, C L Armour, S Z Bosnic- \\ Anticevich, F C K Thien, C R Jenkins
}

See end of article for authors' affiliations .....................

Correspondence to: C A Slader, Faculty of Pharmacy, University of Sydney, New South Wales, Australia 2006 : cassandra@pharm.usyd. edu.au

Received 20 October 2005 Accepted 23 February 2006 Published Online First 5 June 2006

\begin{abstract}
Background: Previous studies have shown that breathing techniques reduce short acting $\beta_{2}$ agonist use and improve quality of life (QoL) in asthma. The primary aim of this double blind study was to compare the effects of breathing exercises focusing on shallow nasal breathing with those of non-specific upper body exercises on asthma symptoms, QoL, other measures of disease control, and inhaled corticosteroid (ICS) dose. This study also assessed the effect of peak flow monitoring on outcomes in patients using breathing techniques.

Methods: After a 2 week run in period, 57 subjects were randomised to one of two breathing techniques learned from instructional videos. During the following 30 weeks subjects practised their exercises twice daily and as needed for relief of symptoms. After week 16, two successive ICS downtitration steps were attempted. The primary outcome variables were QoL score and daily symptom score at week 12.

Results: Overall there were no clinically important differences between the groups in primary or secondary outcomes at weeks 12 or 28. The QoL score remained unchanged $(0.7$ at baseline $v 0.5$ at week 28, $p=0.11$ both groups combined), as did lung function and airway responsiveness. However, across both groups, reliever use decreased by $86 \%(p<0.0001)$ and ICS dose was reduced by $50 \%(p<0.0001$; $\mathrm{p}>0.10$ between groups). Peak flow monitoring did not have a detrimental effect on asthma outcomes. Conclusion: Breathing techniques may be useful in the management of patients with mild asthma symptoms who use a reliever frequently, but there is no evidence to favour shallow nasal breathing over non-specific upper body exercises.
\end{abstract}

$\mathrm{B}$ reathing techniques are among the most popular complementary medicine modalities used by people with asthma. ${ }^{1-4} \mathrm{~A}$ Cochrane review concluded that breathing exercises for asthma, such as Buteyko, yoga and diaphragmatic breathing, led to decreased use of short acting $\beta_{2}$ agonists and a trend towards improvement in quality of life, but no consistent evidence of improved disease control such as reduced requirement for anti-inflammatory medication, reduced airway hyperresponsiveness, or improved lung function. ${ }^{5}$ Some proponents of breathing techniques have suggested that the failure to demonstrate improvement in lung function measures such as ambulatory peak expiratory flow (PEF) was due to the deep inspirations and forced expirations required with such monitoring. ${ }^{6}$ Additionally, the Cochrane review ${ }^{5}$ highlighted the need for further studies to evaluate the impact of breathing techniques on symptom free days, physiological measurements, and airway inflammation.

This study was designed to test the hypothesis that breathing techniques aimed at reducing tidal volume and rate of breathing and encouraging the nasal route of breathing would result in greater improvement in asthma symptoms and measures of disease control, and allow a greater reduction of inhaled corticosteroid (ICS) use than non-specific upper body exercises. A secondary hypothesis was that twice daily peak flow monitoring has no detrimental effect on asthma outcomes during treatment with either form of breathing exercise.

\section{METHODS}

\section{Subjects}

The study was conducted at a respiratory research institute in Sydney and a tertiary referral hospital in Melbourne, Australia. Subjects with stable suboptimally controlled asthma were identified from a database of volunteers and from advertising in the lay press. All subjects gave informed written consent and the institutional ethics committees of Royal Prince Alfred Hospital, Camperdown and The Alfred Hospital, Melbourne approved the study. Inclusion criteria were: age $15-80$ years, as-needed reliever use $\geqslant 4$ occasions/ week, use of ICS ( $\geqslant 200 \mu \mathrm{g} /$ day for $\geqslant 3$ months with no dose change during the previous 4 weeks), current non-smoker, forced expiratory volume in 1 second $\left(\mathrm{FEV}_{1}\right) \geqslant 50 \%$ and $<90 \%$ predicted or $\mathrm{FEV}_{1}$ /forced vital capacity (FVC) ratio $<70 \%$, reversibility $\geqslant 200 \mathrm{ml}$ to bronchodilator within previous 6 months, and daily access to television/video player. Exclusion criteria included current smoking or $>10$ packyear smoking history, recently unstable asthma, and prior tuition in Buteyko (for full details see online supplement at http://www.thoraxjnl.com/supplemental).

\section{Study design}

The study was a double blind, randomised, controlled, multicentre comparison of two breathing techniques-one (group A) aimed at reducing tidal volume, reducing hyperventilation and encouraging nasal route of breathing, and the other (group B) involving non-specific upper body mobility exercises. After a 2 week run in period on preexisting treatment, subjects were randomised (fig l) using computer generated permuted blocks (block size of four). Subjects learned and practised their exercises by video

Abbreviations: $A C Q$, Asthma Control Questionnaire; $A Q L Q, A s t h m a$ Quality of Life Questionnaire; $\mathrm{FEV}_{1}$, forced expiratory volume in 1 second; FVC, forced vital capacity; ICS, inhaled corticosteroid; PEF, peak expiratory flow 
instruction (see details under Interventions section and in table 1). They were asked to practise their routine exercises twice daily (approximately 26 minutes). For symptoms normally requiring reliever, subjects in both groups were advised to use a shorter set of their allocated breathing exercises (3-5 minutes) first and to take reliever if symptoms persisted. Dose reductions in ICS of $50 \%$ were attempted at weeks 16 and 22 for eligible subjects (see online supplement).

\section{Interventions}

In the videos the duration, format, and style of presentation were matched for both groups. All subjects were provided with a detailed "Instruction" video for initial teaching and a "Daily Exercises" video. They were instructed to practise their exercises twice daily, watching the video at least once daily. The "Instruction" video could be used again at any time. An unblinded research assistant contacted the subjects at 2 weekly intervals to review the essential elements of the breathing exercises, answer questions, and clarify concerns. Subjects were also offered face to face tuition.

\section{Outcome measurements}

All measurements were made by trained research assistants who were blinded to the subjects' treatment allocation. Baseline data were collected at week 0. At each visit, spirometry was measured and airway resistance was recorded using the forced oscillation technique. ${ }^{7}$ Route of breathing (primarily nasal, primarily oral, mixed) was established from headset mounted thermistor recordings, and end tidal $\mathrm{CO}_{2}$ measurements from exhaled breath, while subjects were distracted with questionnaire tasks. Airway responsiveness to mannitol $^{8}$ was assessed at all visits except week -2 . Patient and Physician Global Assessments of Asthma Control were recorded on a visual analogue scale at all visits, and the Asthma Control Questionnaire (ACQ) ${ }^{9}$ and Asthma Quality of Life Questionnaire-Sydney (AQLQ) ${ }^{10}$ range 0-4 (bestworst quality of life) were administered at all visits except week 6.

Subjects used electronic diary spirometers (AM2, Erich Jaeger GmbH, Hoechberg, Germany) twice daily to record symptom intensity, night waking, use of reliever, Global Assessment of Asthma Control, time spent doing routine study exercises, and number of times exercises were used for symptom relief. $\mathrm{FEV}_{1}$ and PEF were obtained from the three 2 week periods of spirometric recordings (fig 1).

Changes in medications, exacerbations, and adverse events were recorded at all visits. Moderate exacerbations were defined as $\geqslant 2$ consecutive days of increased reliever use by $>2$ occasions/day and/or increase in symptoms ( $\geqslant 1$ episode of nocturnal asthma/night and/or early waking requiring reliever) over baseline, and/or in the investigator's opinion the subject was experiencing an exacerbation. They were

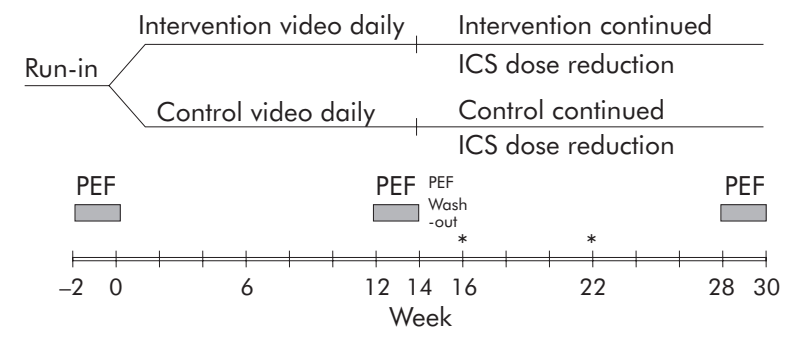

Figure 1 Schematic of study design. Inhaled corticosteroid (ICS) dose remained constant until week 16, after which two successive dose reductions of $50 \%$ were attempted for subjects who satisfied the eligibility for reduction criteria (weeks 16 and 22). *ICS dose reduction if clinically indicated (both groups).
Table 1 Exercise descriptions

\begin{tabular}{|c|c|c|}
\hline & Group A & Group B* \\
\hline \multicolumn{3}{|c|}{ Daily exercises } \\
\hline \multirow[t]{3}{*}{ Components } & Hypoventilation & $\begin{array}{l}\text { Shoulder rotations, forward } \\
\text { curls, arm raises with } \\
\text { controlled inspiratory- } \\
\text { expiratory cycles }\end{array}$ \\
\hline & $\begin{array}{l}\text { Breath hold at functional } \\
\text { residual capacity }\end{array}$ & $\begin{array}{l}\text { "Control of breathing": } \\
\text { focusing on good posture } \\
\text { and relaxation }\end{array}$ \\
\hline & Nasal route of breathing & $\begin{array}{l}\text { Route of breathing not } \\
\text { specified, with both mouth } \\
\text { and nasal breathing } \\
\text { demonstrated }\end{array}$ \\
\hline $\begin{array}{l}\text { Twice daily } \\
\text { routine }\end{array}$ & $\begin{array}{l}\text { Above components } \\
\text { performed in: } \\
3 \text { minute cycles for } \\
\text { approximately } 13 \text { minutes }\end{array}$ & $\begin{array}{l}\text { Above components } \\
\text { performed in: } \\
3 \text { minute cycles for } \\
\text { approximately } 13 \text { minutes }\end{array}$ \\
\hline & $\begin{array}{l}\text { While seated } \\
\text { Accompanied by footage } \\
\text { of scenery }\end{array}$ & While seated \\
\hline \multicolumn{3}{|c|}{ Symptom relief exercises } \\
\hline & $\begin{array}{l}\text { Shorter version of routine } \\
\text { exercises }\end{array}$ & $\begin{array}{l}\text { "Control of breathing" } \\
\text { exercises with or without } \\
\text { physical manoeuvres }\end{array}$ \\
\hline & $\begin{array}{l}\text { Reliever use instruction: } \\
\text { If symptoms are not } \\
\text { relieved at first by the } \\
\text { exercises, try them again } \\
\text { If symptoms persist, use } \\
\text { reliever }\end{array}$ & $\begin{array}{l}\text { Reliever use instruction: } \\
\text { If symptoms are not relieved } \\
\text { at first by the exercises, try } \\
\text { them again } \\
\text { If symptoms persist, use } \\
\text { reliever }\end{array}$ \\
\hline
\end{tabular}

*These exercises were designed to avoid impact on upper body muscle strength.

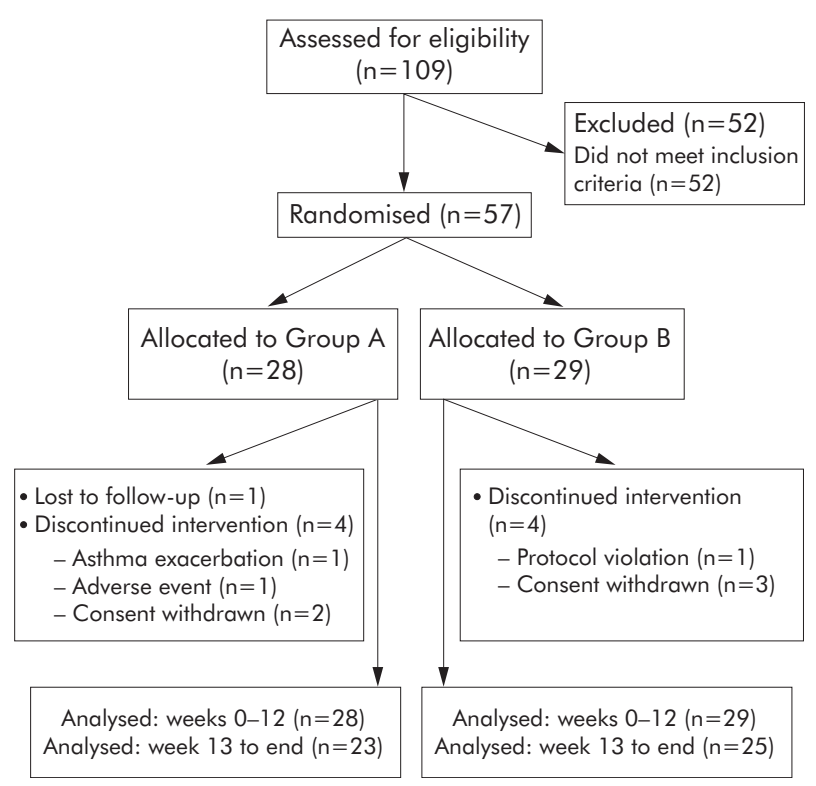

Figure 2 Patient disposition.

treated with double dose ICS for 2 weeks. Severe exacerbations were defined by requirement for oral corticosteroids.

\section{Analysis of data}

Analysis was based on intention-to-treat, with all data from both centres combined. Handling of subject withdrawals and missing data are described in the online supplement.

The primary outcome analyses were AQLQ (total) score and daily symptom score between groups at week 12 (completion of ICS maintenance phase), with adjustment for baseline. All outcome variables were compared between groups at weeks 12 and 28. Outcome variables were also 
Table 2 Baseline demographic and clinical characteristics of the study population

\begin{tabular}{|c|c|c|c|}
\hline Characteristic & Group A $(n=28)$ & Group B $(n=29)$ & $p$ value \\
\hline $\operatorname{Sex}(M: F)$ & $11: 17$ & $14: 15$ & 0.6768 \\
\hline Smoking history (never : former) & $19: 9$ & $23: 6$ & 0.4960 \\
\hline Atopy (non-atopic : atopic) ${ }^{\star \star}$ & $2: 23$ & $4: 23$ & 0.7383 \\
\hline $\begin{array}{l}\text { Oral corticosteroid use in past } \\
\text { year (\%) }\end{array}$ & 42.9 & 27.6 & 0.2143 \\
\hline $\mathrm{FEV}_{1}(\% \text { predicted })^{*}$ & 80.78 (74.52 to 87.03$)$ & 78.93 (72.48 to 85.38$)$ & 0.6760 \\
\hline Reliever use (puffs/day)* & 2.94 (2.09 to 3.79$)$ & $3.09(2.22$ to 3.95$)$ & 0.8066 \\
\hline AQLQ* $\ddagger$ & $0.77(0.57$ to 0.96$)$ & $0.54(0.43$ to 0.65$)$ & 0.0417 \\
\hline$A C Q-7 * \pi$ & $1.46(1.22$ to 1.70$)$ & $1.37(1.16$ to 1.58$)$ & 0.5653 \\
\hline Daytime symptom intensity score†§ & $2.00(1.00-3.00)$ & $2.00(1.00-3.00)$ & 0.7251 \\
\hline \multicolumn{4}{|c|}{$\begin{array}{l}\text { FEV } 1 \text {, forced expiratory volume in } 1 \text { second; AQLQ, Asthma Quality of Life Questionnaire; ACQ, Asthma Control } \\
\text { Questionnaire. } \\
\text { "Mean ( } 95 \% \text { CI). } \\
\text { †Median (IQR). } \\
\text { †Range (best-worst): } 0-4 ; \\
\text { - Range (best-worst): } 0-6 \text {; } \\
\text { \$Range (none-severe): } 1-5 \\
\text { *A Atopic was defined as a positive skin prick test using the following criteria: length } \times \text { width any allergen from a } \\
\text { standard panel } \geqslant \text { length } \times \text { width saline and } \geqslant 3 * 3 \text {. }\end{array}$} \\
\hline
\end{tabular}

compared within groups at weeks 12 and 28. The impact of PEF monitoring was assessed by comparing outcome variables before and after PEF monitoring for clinic measurements (week $12 v$ week 14, week $28 v$ week 30), and with and without PEF monitoring for diary variables. Outcomes were compared using unpaired (two sample) $t$ tests adjusted for baseline and paired $t$ tests for normally distributed data, and by Mann-Whitney $U$ and Wilcoxon tests for non-parametric data. Because the ACQ includes a question about reliever use, questions 1-6 (ACQ-6: lung function data removed) and questions 1-5 (ACQ-5: lung function and reliever data removed) were also analysed. ${ }^{11}$

The sample size of 50 subjects was calculated based on detecting a clinically meaningful difference $(0.5)$ in AQLQ score between groups with $80 \%$ power $(\alpha=0.05)$. To detect a 0.5 change in symptom score $(80 \%$ power, $\alpha=0.05)$, a total sample size of 80 was required.

\section{RESULTS}

Fifty seven subjects were randomised (28 to group A and 29 to group B). Nine subjects (five from group A and four from group B) withdrew before completion of the study (fig 2). Blinding of randomisation allocation was not broken for any subject. Baseline demographic and clinical characteristics are shown in table 2. At baseline, subjects had mild airway obstruction and used on average 3 puffs reliever/day. Asthma related quality of life was well preserved and was slightly better in group $B$ at baseline $(p=0.0417)$. There were no significant differences in other variables.

During the study there was no significant difference between the groups in the self-reported time spent on routine daily exercises (group A: median $12 \mathrm{~min} /$ day (IQR 7-20); group B: $16 \mathrm{~min} /$ day (IQR 8-20); $\mathrm{p}=0.66$ ). Median overall adherence to twice daily electronic monitoring was $62 \%$.

\section{Primary outcome measures}

Primary outcome measures are shown in table 3. At week 12 there was no significant difference between the two groups in AQLQ score $(p=0.29)$. There were small differences favouring group $B$ in daytime symptom scores $(p=0.0192)$ and night-time symptom scores $(\mathrm{p}=0.0636)$.

\section{Secondary outcome measures (weeks 1-12)}

\section{Reliever use}

Both groups had a dramatic reduction in reliever use commencing from week 1 after randomisation (fig 3), with no significant differences between the groups at week 12. The proportion of reliever-free days increased in both groups between baseline and week 12 (group A: median baseline $6.7 \%$, week $1253.5 \%, \mathrm{p}=0.001$; group B: baseline $8.3 \%$, week $1255.3 \%, p=0.0001$ ) with no significant differences between groups $(p=0.49$ at baseline; $p=0.19$ at week 12$)$.

\section{Other variables}

There was no significant difference between ACQ scores at week $12(p=0.234)$. However, there was a statistically significant improvement in ACQ at week 12 in group B $(\mathrm{p}=0.0324)$ but not in group A $(\mathrm{p}=0.49$; see online supplement). A significant improvement in ACQ was seen for group B even when the components for $\beta_{2}$ agonist use and lung function were omitted (see online supplement).

There were no significant differences between groups in Patient or Physician Global Assessments at week 12, although Physician Global Assessment improved significantly for group B but not group A compared with baseline $(\mathrm{p}=0.0467$ and $\mathrm{p}=0.073$, respectively $)$.

There was no significant difference between groups in clinic $\mathrm{FEV}_{1}$ at week $12(\mathrm{p}=0.30)$, although there was a small reduction in $\mathrm{FEV}_{1}(0.084 \mathrm{l})$ by week 12 in group $\mathrm{B}$ $(p=0.0359)$. There were no consistent differences between the two groups at week 12 for airway responsiveness to mannitol, or for mean airway resistance before and after deep inspiration. The airway responsiveness data need to be interpreted with caution due to missing data (see online supplement).

There was no difference between the groups at week 12 in volume of deep inspiration and number of breaths per minute (see online supplement), end tidal $\mathrm{CO}_{2}$, or route of breathing, and no significant changes in any of these measures within either group during weeks $0-12$. The end tidal $\mathrm{CO}_{2}$ and route of breathing data need to be interpreted with caution due to missing data (see online supplement).

\section{Inhaled corticosteroid dose reduction (weeks 13-28) ICS dose}

At baseline, median daily ICS dose (BDP equivalent) was $800 \mu \mathrm{g} \quad(\mathrm{IQR}$ 758-1900, $\mathrm{n}=28$ ) and $800 \mu \mathrm{g} \quad(500-2000$, $\mathrm{n}=29)$ for groups $\mathrm{A}$ and $\mathrm{B}$, respectively $(\mathrm{p}=0.92)$. The final ICS dose was $200 \mu \mathrm{g}(100-275, \mathrm{n}=23)$ and $187.5 \mu \mathrm{g}(119-$ $250, \mathrm{n}=25$ ), respectively. The mean reduction in ICS dose for those who remained in the study beyond week 13 was $50 \%$ (IQR 50-75, p <0.0001 compared with baseline (both groups combined, $\mathrm{n}=48$ ). 
Table 3 Primary and secondary outcome measures: comparison between groups

\begin{tabular}{|c|c|c|c|c|c|c|c|}
\hline \multirow[b]{2}{*}{ Outcome measure } & \multicolumn{2}{|l|}{ Baseline } & \multirow{2}{*}{$\begin{array}{l}\text { Difference at week } 12^{\star *} \\
\text { end stable ICS dose } \\
(95 \% \mathrm{CI})\end{array}$} & \multirow{2}{*}{$\begin{array}{l}\text { Difference at week } 28^{\star *} \\
\text { end ICS reduction } \\
(95 \% \mathrm{CI})\end{array}$} & \multicolumn{3}{|c|}{$\begin{array}{l}\text { Comparison between groups } \\
\text { ( } \mathrm{p} \text { value) }\end{array}$} \\
\hline & Group A & Group B & & & Base & Week 12 & 2 Week 28 \\
\hline AQLQ - total* $\uparrow$ & $0.77(0.50)$ & $0.54(0.30)$ & $\begin{array}{l}0.14(-0.13 \text { to } 0.41) \\
\text { [Missing: } A: 3, B: 2]\end{array}$ & $0.14(-0.11$ to 0.38$)$ & 0.04 & 0.29 & 0.27 \\
\hline Day symptom intensity score† $\bullet$ & $2.00(2.00)$ & $2.00(2.00)$ & $\begin{array}{l}0.45 \text { (0.09 to } 0.81) \\
\text { [Missing: } A: 2, B: 2 \text { ] }\end{array}$ & $\begin{array}{l}0.27 \text { (-0.21 to } 0.75) \\
\text { [Missing: B:3] }\end{array}$ & 0.73 & 0.02 & 0.26 \\
\hline Night symptom intensity score† & $2.00(1.00)$ & $2.00(1.00)$ & $\begin{array}{l}0.34(-0.02 \text { to } 0.70) \\
\text { [Missing: } A: 2, B: 3]\end{array}$ & $\begin{array}{l}0.27(-0.14 \text { to } 0.68) \\
\text { [Missing: } B: 4 \text { ] }\end{array}$ & 0.53 & 0.06 & 0.20 \\
\hline Symptom free days $(\%)^{* * * *}$ & $23.51(26.83)$ & $22.07(30.45)$ & $\begin{array}{l}-4.25 \text { ( }-14.45 \text { to } 5.96) \\
\text { [Missing: } A: 2, B: 2 \text { ] }\end{array}$ & $\begin{array}{l}-8.56 \text { ( }-22.74 \text { to } 5.61) \\
\text { [Missing: } B: 3 \text { ] }\end{array}$ & 0.85 & 0.81 & 0.23 \\
\hline Reliever use (puffs/day) ${ }^{*}$ ฯฯ & $2.94(2.20)$ & $3.09(2.28)$ & $\begin{array}{l}0.51 \text { (-0.22 to } 1.23) \\
\text { [Missing: } A: 2, B: 2 \text { ] }\end{array}$ & $\begin{array}{l}0.005 \text { ( }-0.98 \text { to } 0.99 \text { ) } \\
\text { [Missing: } B: 3 \text { ] }\end{array}$ & 0.81 & 0.17 & 0.99 \\
\hline Reliever free days $(\%) \dagger \dagger^{* \star *}$ & $6.67(42.42)$ & $8.33(41.67)$ & $\begin{array}{l}-4.85(-23.90 \text { to } 14.21) \\
\text { [Missing: } A: 2, B: 2 \text { ] }\end{array}$ & $\begin{array}{l}1.89 \text { (-18.49 to } 22.27 \text { ) } \\
\text { [Missing: } B: 3 \text { ] }\end{array}$ & 0.49 & 0.19 & 0.63 \\
\hline ACQ-7§* & $1.46(0.61)$ & $1.37(0.55)$ & $\begin{array}{l}0.21(-0.14 \text { to } 0.56) \\
\text { [Missing: } A: 1]\end{array}$ & $0.11(-0.20$ to 0.43$)$ & 0.57 & 0.23 & 0.47 \\
\hline Patient Global Assessment* $\ddagger \ddagger$ & $61.32(24.89)$ & $66.17(20.76)$ & $\begin{array}{l}-6.21(-18.66 \text { to } 6.23) \\
\text { [Missing: } B: 1]\end{array}$ & $-4.84(-17.49$ to 7.82$)$ & 0.43 & 0.32 & 0.45 \\
\hline Physician Global Assessmentł‡ & $61.43(15.14)$ & $62.31(15.89)$ & $-1.15(-10.25$ to 7.95$)$ & $-2.37(-10.33$ to 5.60$)$ & 0.83 & 0.80 & 0.55 \\
\hline Lung function $\left(\mathrm{FEV}_{1} \%\right.$ predicted) ${ }^{\star} \dagger \dagger$ & $80.78(16.14)$ & $78.93(16.96)$ & $1.94(-1.77$ to 5.64$)$ & $-2.27(-6.02$ to 1.49$)$ & 0.68 & 0.30 & 0.23 \\
\hline Lung function (FVC\% predicted)* & $103.09(19.22)$ & $101.55(18.01)$ & $2.41(-3.09$ to 7.91$)$ & $-0.18(-5.51$ to 5.16$)$ & 0.76 & 0.38 & 0.95 \\
\hline End tidal $\mathrm{CO}_{2}(\%) \dagger \S \S$ & $4.14(1.90)$ & $3.77(1.17)$ & $\begin{array}{l}-0.20(-1.03 \text { to } 0.24) \\
\text { [Missing: } A: 3, B: 5]\end{array}$ & $\begin{array}{l}0.28(-0.22 \text { to } 0.91) \\
\text { [Missing: } A: 1, B: 3]\end{array}$ & 0.71 & 0.37 & 0.26 \\
\hline Route of breathing (nasal/\%) & $16 / 20(80 \%)$ & $13 / 23(57 \%)$ & $\begin{array}{l}\text { A: } 14 / 19(73.68 \%) \\
\text { B: } 14 / 21(66.67 \%) \\
\text { Ratios at week } 12^{\star *} \\
\text { (95\% Cl of ratio) }\end{array}$ & $\begin{array}{l}\text { A: } 14 / 14(100 \%) \\
\text { B: } 7 / 17(41.18 \%) \\
\text { Ratios at week } 28^{\star *} \\
(95 \% \mathrm{Cl} \text { of ratio) }\end{array}$ & $\begin{array}{l}0.1936 \\
\text { Compari } \\
\text { (p value) }\end{array}$ & $\begin{array}{l}0.3970 \\
\text { son betwe }\end{array}$ & 0.0023 \\
\hline RDR mannitol (\% fall/mg) & $0.02(30.16)$ & $0.18(1.19)$ & $\begin{array}{l}1.17 \text { (0.69 to } 1.99) \\
\text { [Missing: } A: 12, B: 16 \text { ] }\end{array}$ & $\begin{array}{l}0.79(0.50 \text { to } 1.25) \\
\text { [Missing: A:10, B:12] }\end{array}$ & 0.28 & 0.54 & 0.30 \\
\hline \multicolumn{8}{|c|}{ 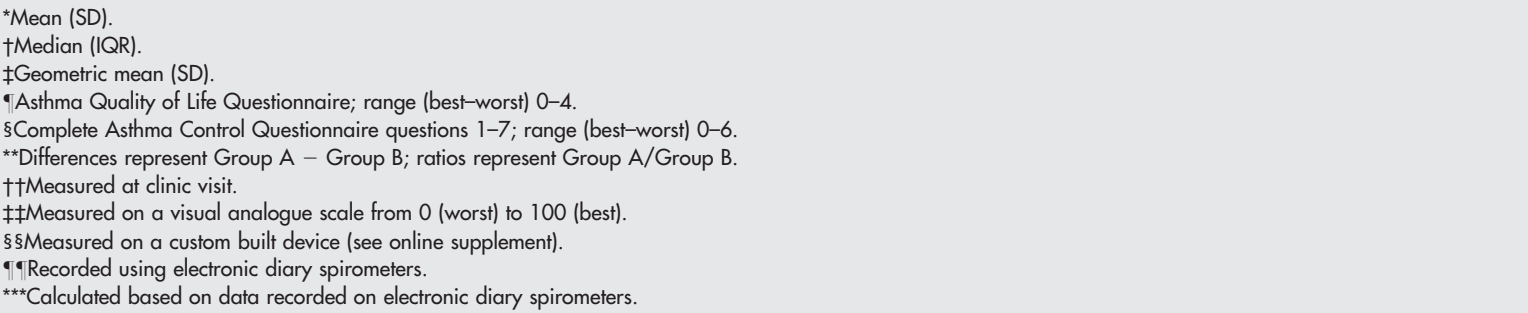 } \\
\hline
\end{tabular}

\section{Clinical outcomes after ICS dose reduction}

At week 28 there was no significant difference between groups in AQLQ score, daytime or night time symptom scores, reliever use, symptom-free days, Patient or Physician Global Assessments, ACQ scores, $\mathrm{FEV}_{1}$, mean airway resistance before and after deep inspiration, airway responsiveness to mannitol, or end tidal $\mathrm{CO}_{2}$ adjusted for baseline (table 3). Data for mannitol challenge, route of breathing, and end tidal $\mathrm{CO}_{2}$ were not available for all subjects at week 28 (see online supplement), and these results therefore need to be interpreted with caution. Of 31 subjects with route of

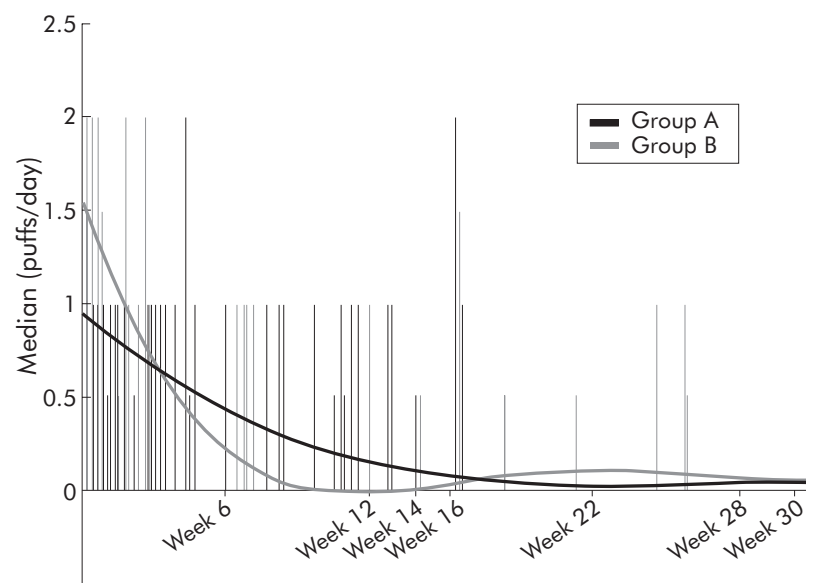

Figure 3 Reliever use reduction. breathing data, more subjects breathed nasally in group A than in group B. Stability of asthma was maintained in both treatment groups during reduction in ICS dosage. This was demonstrated by maintenance of, or improvement in, asthma outcomes at week 28 compared with week 12 (see online supplement).

\section{Adverse events}

Twelve moderate exacerbations were experienced by 11 subjects (three in group $\mathrm{A}$ and eight in group $\mathrm{B}, \mathrm{p}=0.11$ ) during the study. There were 259 other adverse events ( 138 in group A and 121 in group B), none of which was considered to be related to treatment. Eight adverse events (five in group A and three in group B) were attributed to mannitol (see online supplement).

\section{Potential impact of PEF monitoring on other asthma outcomes}

There were no significant differences in any outcome variables between these periods, with the exception of AQLQ in group B for week $12 v$ week $14(\mathrm{p}=0.024)$ where the difference favoured the post-PEF period (see online supplement).

\section{DISCUSSION}

This study found that similar improvements in asthma symptoms, reliever use, and ICS dose were achieved in subjects with mild to moderate asthma using a technique which focused on the nasal route of breathing, hypoventilation, and breath holding, and a breathing technique incorporating non-specific upper body manoeuvres. 
Importantly, these changes were achieved without impacting negatively on underlying disease control, as measured by lung function and airways responsiveness. Devising a credible control for complementary medicine interventions has been acknowledged as a difficult task, ${ }^{12-15}$ and previous studies examining breathing exercises for asthma have used a variety of control arms including asthma education and relaxation, but this approach has limited the conclusions which can be drawn about the efficacy of the breathing technique itself. Instead, we used a second breathing technique for which there was no previous evidence of efficacy in a randomly selected asthma population, and in which there was no attempt to modulate pattern of breathing. Unlike previous studies, ${ }^{16-23}$ we also matched all process elements of the two interventions, including the instruction about symptom relief, so that the only variable was the exercises themselves. The similarity of the improvements seen in both groups, despite the widely disparate nature of the breathing exercises they were using, suggests that the observed changes were more likely to be attributable to one or more of the shared process elements-such as the instruction to use the exercises initially in place of reliever for symptom relief-than to the breathing exercises themselves.

Although we found significant improvements in reliever use, some patient centred outcomes and ICS dose, there were no significant changes in physiological parameters. With one exception, ${ }^{18}$ no previous study of breathing techniques has found an improvement in lung function ${ }^{5}$ or airway hyperresponsiveness, ${ }^{19}$ and there is no evidence that upper body exercises such as those used for group B would impact on lung function. Our results confirm no change in end tidal $\mathrm{CO}_{2}$, as also reported by Bowler et al. ${ }^{16}$ While data for end tidal $\mathrm{CO}_{2}$ and mannitol challenge in the present study should be interpreted with caution due to missing data, these findings - together with the measurement of airway resistance by the forced oscillation technique-strongly suggest that the improvements observed with both breathing techniques were not measurably related to physiological changes.

It has also been suggested ${ }^{6}$ that the failure of previous studies of breathing techniques to demonstrate improvements in lung function was due to a bronchoconstricting effect of deep breaths during PEF monitoring. However, we failed to find evidence that 2 week periods of PEF monitoring were detrimental, with even small improvements occurring in some measures. Our findings therefore suggest that breathing techniques do not mask any benefit or cause deterioration in other measures of asthma control.

Previous studies of breathing techniques have shown a trend towards a reduction in ICS dose. We found a significant and similar reduction in ICS dose in both groups, with no negative impact on other outcome measures. It is unlikely that this was due to improvement in airway inflammation, given the lack of change in indirect airway hyperresponsiveness. However, some of our subjects may have been relatively overtreated with ICS at entry, as many clinicians rely on markers such as reliever use to indicate whether a patient's ICS dose is appropriate. Further, other researchers have been able to reduce ICS doses by approximately $50 \%$ in a clinical trial setting in the absence of any other intervention. ${ }^{24}$ Despite the lack of physiological improvement, any strategy which facilitates ICS reduction has important clinical implications and useful applications.

There are several possible mechanisms to explain the reliever reduction observed in this study. One possibility is that this effect was due to participation in a clinical trial (Hawthorne effect ${ }^{25}$ ). However, this would be an oversimplification given that reliever reduction was substantial
( $86 \%$ by study end) and was sustained over 8 months. For both groups there were more symptom-free days at baseline (group A: $23.5 \%$, group B: $22.1 \%$ ) than reliever-free days (group A: 6.7\%, group B: 8.3\%). Similar disparities have been observed in other asthma studies, ${ }^{26}$ suggesting that patients may often use their reliever for prevention rather than actual relief of symptoms. Presumably, any instruction which defers or delays the taking of a $\beta_{2}$ agonist will minimise its habitual and pre-emptory use. Thus, while breathing exercises may not confer any particular physiological benefit, the process of using breathing techniques as first line symptom treatment may allow people to substantially reduce their use of $\beta_{2}$ agonist. This itself may be beneficial by reducing adrenergic side effects, by reducing response to allergens, or by reducing mast cell tachyphylaxis. ${ }^{27-29}$

Another possible explanation for the overall improvements is that the subjects recruited were a "special" group in terms of their personality or breathing style. No specific tests of personality, anxiety, or depression were administered. The fact that breathing exercises were mentioned in some recruitment material may have attracted subjects who were more likely to respond to the interventions, enabling both breathing techniques to function as "very active placebos". However, the baseline clinical characteristics of the subjects from this study, including symptom and reliever frequency, were similar to those from a more conventional clinical trial recently conducted at the same centres. ${ }^{30}$ While it is possible that the relaxation elements of both interventions assisted in reducing anxiety and hence in reducing the perceived need for reliever, the subscores for the mood domains of the AQLQ (which includes questions about anxiety) were very low in our subjects at baseline, indicating minimal impact of anxiety and-unlike in previous studies ${ }^{16} 1{ }^{12}$-minimal opportunity for improvement in asthma related quality of life. These subscores remained largely unchanged throughout the study, suggesting that the large reduction in $\beta_{2}$ agonist use was not primarily due to the relief of anxiety. There has been considerable interest in the concepts of dysfunctional breathing and hyperventilation syndrome, ${ }^{31}$ but the clinical importance of such conditions in people with asthma has not yet been established. The Nijmegen questionnaire has been used to assess dysfunctional breathing, but was not included in the present study as there is considerable overlap with the symptoms of asthma itself. A previous study of asthmatic patients with high Nijmegen scores showed improved quality of life with a breathing technique similar to our group B intervention, but there was no reduction in reliever use or ICS dose. ${ }^{23}$ Although some patients in the present study may have satisfied the criteria for hyperventilation, the randomisation process should have ensured that they were equally distributed between both treatment arms.

Although there was little change in AQLQ score, improvements were seen in other patient centred outcome measures including Patient Global Assessment of Control and ACQ scores. These improvements suggest that the subjects' selfefficacy was enhanced, which may have been due to a reduction in medication facilitated by breathing techniques. While the "ideal" study would include a group of control subjects who were instructed to withhold reliever without any substitute, gaining the agreement of subjects and the approval of an ethics committee would undoubtedly be difficult. In the present study, subjects in both groups were provided with a strategy that offered an alternative to reliever use which they appeared to accept as plausible and credible. We suggest that the combination of these factors enabled patients to reduce their reliever use in the absence of any other change.

In summary, this study shows that two completely different types of breathing techniques, taught by video, 
can lead to a similar level of improvement in asthma outcomes particularly those relating to the use of a short acting $\beta_{2}$ agonist. These improvements are of a magnitude similar to that observed in conventional clinical trials which assess pharmacological interventions to improve asthma control, and are therefore clinically important. The improvement observed was substantial and sustained, but was not associated with a measurable effect on physiological parameters of airway inflammation. Given the magnitude of the differences in content of the two breathing techniques which were used in the present study, it appears likely that the observed clinical improvements were not due to the use of a particular type of exercise but to the process of both routine and as-required exercises that reinforce a message of relaxation and self-efficacy and provide a deferral strategy for $\beta_{2}$ agonist use. Breathing techniques may be useful in the management of patients with mild asthma symptoms who use reliever frequently, but at present there is no evidence to favour shallow breathing techniques over non-specific upper body manoeuvres.

\section{ACKNOWLEDGEMENTS}

The authors acknowledge the valuable assistance of Associate Professor Guy B Marks for additional statistical advice, Ms Karen Symons, Ms Susan Forrest-Blythe and Ms Caroline Reddel for assisting with data collection, Dr Ciça Santos (unblinded medical officer), Mr Nathan Brown, Mr Phillip Munoz and Dr Cheryl Salome for assistance with the forced oscillation technique, Dr John Brannan and Dr Sandy Anderson for assistance with the mannitol challenge, Mr Gunnar Ungar and Mr Tom Li for devising and constructing the $\mathrm{CO}_{2}$ - $\mathrm{ROB}$ headset, $\mathrm{Mr}$ Aneal Chandra for devising the analysis software for $\mathrm{CO}_{2}$-ROB data, and Dr Jenny Alison for advice regarding the Group B exercises.

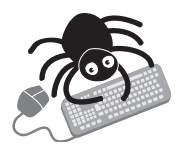

Further details are given in the online supplement available at http://www.thoraxinl.com/supplemental.

\section{Authors' affiliations}

C A Slader, Co-operative Research Centre for Asthma, University of Sydney, and Faculty of Pharmacy, University of Sydney, Australia H K Reddel, E G Belousova, C R Jenkins, Co-operative Research Centre for Asthma, University of Sydney, and Woolcock Institute of Medical Research, Camperdown, Australia

L M Spencer, Department of Physiotherapy, Royal Prince Alfred Hospital, Camperdown, Australia

C L Armour, S Z Bosnic-Anticevich, University of Sydney, Sydney, Australia

F C K Thien, Co-operative Research Centre for Asthma, Department of Allergy, Immunology and Respiratory Medicine, The Alfred Hospital, and Monash University, Melbourne, Australia

This study was conducted under the auspices of the Cooperative Research Centre for Asthma, jointly funded by the Australian Federal Government and industry, including AstraZeneca, Aventis Pharma, and GlaxoSmithKline. HR was funded by the Asthma Foundation of New South Wales. CS was funded by the Australian Government Department of Education, Science and Training via an Australian Postgraduate Award.

Competing interests: none.

\section{REFERENCES}

1 Ernst E. Complementary therapies for asthma: what patients use. J Asthma 1998;35:667-71.

2 Ernst $\mathrm{E}$. Use of complementary therapies in childhood asthma. Pediatr Asthma Allergy Immunol 1998;12:29-32.

3 Shenfield G, Lim E, Allen H. Survey of the use of complementary medicines and therapies in children with asthma. J Paediatr Child Health 2000;38:252-7.

4 Partridge MR, Dockrell M, Smith NM. The use of complementary medicines by those with asthma. Respir Med 2003;97:436-8.

5 Holloway E, Ram F. Breathing exercises for asthma. Cochrane Database Syst Rev 2004;3.

6 Kolb P. Buteyko guide for doctors. Buteyko Natural Therapy, 2004. Available at http://members.westnet.com.au/pkolb/doc-a4g.pdf.

7 Salome C, Thorpe C, Diba C, et al. Airway re-narrowing following deep inspiration in asthmatic and nonasthmatic subjects. Eur Respir J 2003;22:62-8

8 Brannan J, Koskela H, Anderson S, et al. Responsiveness to mannitol in asthmatic subjects with exercise- and hyperventilation-induced asthma. Am J Respir Crit Care Med 1998;158:1120-6.

9 Juniper E, O'Byrne P, Guyatt G, et al. Development and validation of a questionnaire to measure asthma control. Eur Respir J 1999;14:902-7.

10 Marks G, Dunn S, Woolcock A. A scale for the measurement of quality of life in adults with asthma. J Clin Epidemiol 1992:45:461-72.

11 Juniper EF, Svensson K, Mork AC, et al. Measurement properties and interpretation of three shortened versions of the asthma control questionnaire. Respir Med 2005;99:553-8.

12 Margolin M, Avants S, Kleber H. Investigating alternative medicine therapies in randomized controlled trials. JAMA 1998;280:1626-8.

13 Nahin R, Straus S. Research into complementary and alternative medicine: problems and potential. BMJ 2001;322:161-4.

14 Lane D, Lane T. Alternative and complementary medicine for asthma. Thorax 1991:46:787-97.

15 Paterson C, Dieppe P. Characteristics and incidental (placebo) effects in complex interventions such as acupuncture. BMJ 2005;330:1202-5.

16 Bowler SD, Green A, Mitchell CA. Buteyko breathing techniques in asthma: a blinded randomised controlled trial. Med J Aust 1998;169:575-8.

17 Opat A, Cohen M, Bailey M et al. A clinical trial of the Buteyko breathing technique in asthma as taught by a video. J Asthma 2000;37:557-64.

18 Nagarathna R, Nagendra H. Yoga for bronchial asthma: a controlled study. BMJ 1985;291:1077-9.

19 Cooper S, Oborne J, Harrison V, et al. Effects of two breathing exercises (Buteyko and pranayama) in asthma: a randomised controlled trial. Thorax 2003;58:674-9.

20 McHugh P, Aitcheson F, Duncan B, et al. Buteyko breathing technique for asthma: an effective intervention. NZ Med J 2003;116:710-6.

21 Vedanthan PK, Kesavalu LN, Murthy KC, et al. Clinical study of yoga techniques in university students with asthma: a controlled study. Allergy Asthma Proc 1998;19:3-9.

22 Girodo M, Ekstrand K, Metivier G. Deep diaphragmatic breathing: rehabilitation exercises for the asthmatic patient. Arch Physiol Med Rehabil 1992;73:717-20.

23 Thomas M, McKinley R, Freeman E, et al. Breathing retraining for dysfunctional breathing in asthma: a randomised controlled trial. Thorax 2003;58:110-5.

24 Hawkins G, McMahon A, Twaddle S, et al. Stepping down inhaled corticosteroids in asthma: a randomised controlled trial. BMJ 2003;326:1115-20.

25 Mayo E. The Hawthorne Experiment. Western Electric Company. In: The human problems of an industrial civilisation. New York: MacMillan, 1933:55-76.

26 O'Byrne P, Bisgaard H, Goddard P, et al. Budesonide/formoterol combination therapy as both maintenance and reliever medication in asthma. Am J Respir Crit Care Med 2005;171:129-36.

27 Sears $M$, Taylor D, Print C, et al. Regular inhaled beta-agonist treatment in bronchial asthma. Lancet 1990;336:1391-6.

28 Sears $M$, Lotvall J. Past, present and future: $\beta_{2}$-adrenoceptor agonists in asthma management. Respir Med 2005;99:152-70.

29 Taylor D, Sears M. Regular beta-adrenergic agonists: evidence, not reassurance, is what is needed. Chest 1994;106:552-9.

30 Jenkins C, Thien FC, Wheatley J, et al. Traditional and patient-centred outcomes with three classes of asthma medication. Eur Respir J 2005;26:36-44.

31 Thomas M, McKinley R, Freeman E, et al. Prevalence of dysfunctional breathing in patients treated for asthma in primary care: cross sectional survey. BMJ 2001;322:1098-100. 